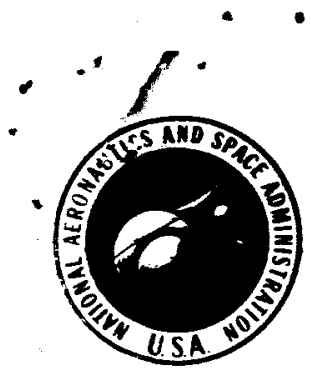

NATIONAL AERONAUTICS AND SPACE ADMINISTRATION

WASHiNGTON, - D.C. 20546

IN REPLY REEER TO:

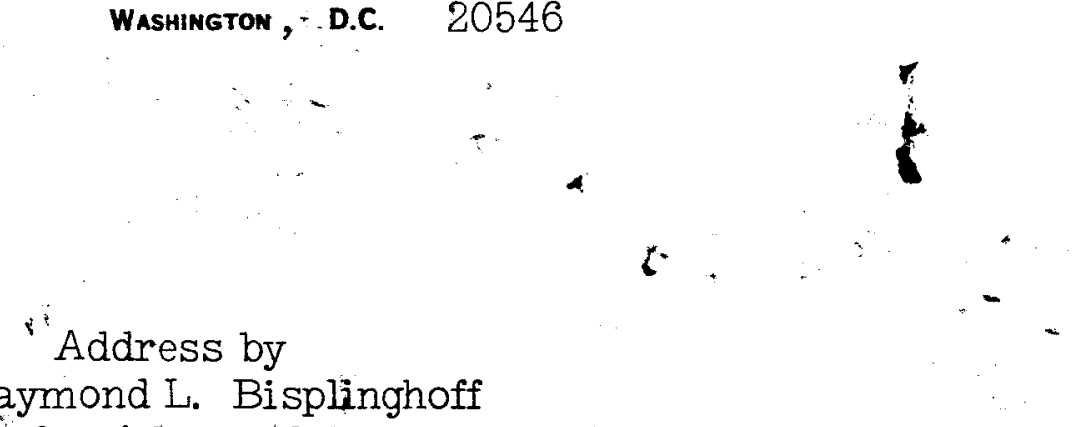

Associate Administrator for Advanced Research and Technology

National Aeronautics and Space Administration

U. C. DAY BANQUET, UNIVERSITY OF CINCINNATI

Cincinnati, Ohlo

April 15, 1964

\title{
SCIENCE AND TECHNOLOGY IN TRANSITION
}

As an alumnus of the University of Cincinnati, I could not be less than deeply honged by your invitation to address you at this U. C. Day Banquet. I shipd like to express this evening some thoughts about science and technology as we find it today, particularly in our aeronautics and space prógrams.

My own association with science and engineering began as a Freshman at the University in the mid-1930's. In those days, before the professional high school guidance counselor made his appearance on the American scene, at least the particular scene that I occupied, I could not have been less prepared for the stimulating years of awak-

< ening at U. C. " It was my good fortune to study under faculty members such as Brand and Justice in Mathematics, Hundley in Mechanics, Wells in Physics, and the late Bradley Jones in Engineering. And then there was Dean Herman Schneider, who exerted during his JJ. C. career a massive influence on engineering education. I refer, in particular, to his leadership in pioneering cooperative engineering education. In remembering Dean Schnider, I cannot refrain from recalling my dissatisfaction, and that of my classmates, with the size of the low speed wind tunnel which the university possessed for instruction and research in 1938. After discussing the matter with Professor Bradley Jones, who described the very severe limitations of the budget, he suggested that we might take up the questions directly with Dean Schneider.

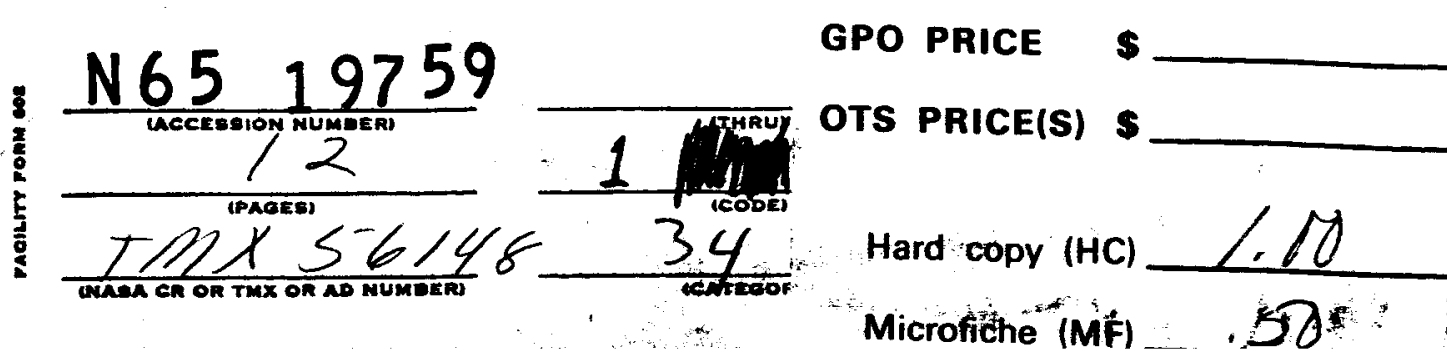


My classmates delegated me to present our case to the Dean who listened carefully while I made as many unfavorable comparisons as possible between our little wind tunnel and those at M. I. T. and Caltech. Dean Schneider replied that he was really not able to judge my argument but that if I would supply him with a description of this little wind tunnel he would seek advice on the matter from his friend, Orville Wright. In another couple of weeks I received a call to come to Dean Schneider's office. He informed me that he had discussed the matter with Orville Wright as he had promised and that Mr. Wright had informed him that the U. C. wind tunnel was much more elaborate than any wind tunnel he had ever employed in his work and that it was, in fact, entirely adequate for instruction and research. I do not know whether you have ever had the experience of being left speechless by overwhelming weight of authority. I can say that I had such an experience on that day in the office of Dean Schneider.

The U. C. wind tunnel in 1938 was, I think, symbolic of the character and relatively modest state of all scientific research a quarter of a century ago. One measure of emphasis on science and technology is the nation's total investment in research and development. In 1938, the combined federal and private investment in research and development stood at roughly a quarter billion dollars in comparison with a figure estimated in excess of 20 billion for 1964. We will have thus experienced about an eightyfold increase in $R$ and $D$ in the 26 years prior to and including 1964 . Over two-thirds of this increase has occurred within the past ten years. We have entered a state of transition which is profoundly changing the political, economic, and social character of the nation. I don't think the dimensions of this transition are generally appreciated. There are, for example, more scientists and engineers at work today than the total number who lived in all the years of the past. Most of the drugs used today to fight disease were not used at all a decade ago. Growth in science and technology appears to follow an exponential law. This is the same law of growth that we find in living systems in which there are no artificial constraints. In other words, the growth is proportional to the amount of science and technology that already exists.

The period of transition of which I speak has sometimes been referred to as the Third Revolution, since it follows in the Twentieth Century the Industrial Revolution of the 19th Century and the American Political Revolution of the 18th Century. The Third or Scientific Revolution will eventually influence the fabric of our nation even more profoundly than the other two. Like the Industrial Revolution, the Scientific Revolution rests on a union of science and craftmanship. 
The steam engine spawned during the Industrial Revolution followed a prototype of today's path from research to development to engineering to exploitation for profit. As you know, steam engine technology flared brightly for a century and a half because it excelled in supplying power needed for pumping water, generating electricity and driving vehicles. The steam engine's successor, the gasoline engine, spanned three quarters of a century in reaching a high level of refinement and application, whereas gas turbine, jet, and rocket engines required only one to two decades after man seriously decided that he wanted them. Nearly a half century was required to bring the vacuum tube to refinement, whereas the transistor was exploited as a substitute in less than a decade. Thus we find today, greatly compressed time scales between the evolution of a concept, and its application.

We find enormous changes in the size and complexity of the enterprises which are used for research and development. Categories of technology are also in a state of transition from those that have existed for decades into entirely new blends of the basic sciences. Space propulsion technology, for example, combines all of the physical sciences. It is truly inter-disciplinary. The evolution of the laser has brought optics into the technology of communications.

Such changes are coming so rapidly that men and institutions are hard put to adjust to them. Arnold Toynbee refers to such rapid changes and the way we force the pace of life as one of the most undesirable aspects of our civilization. It turns out that the engineer is in the most difficult position. A. C. Montieth, former president of the AIEE has said that "today's graduate engineer has a half life of about ten years, " in other words, half of what he knows will be obsolete in a decade. Montieth adds that "half of what he will need to know ten years from now is not available to him today. " This brings to mind the classical story of the medical school dean who confessed to his graduating that half of what they had been taught was incorrect. What is worse, said the dean, we are not sure which half.

The Industrial Revolution and the Scientific Revolution differ, I think, only in that they represent different degrees of involvement between science and craftsmanship. The Industrial Revolution brought on an economic structure that could not be operated without knowledge of the equivalence of different forms of energy. It was necessary to put comparative prices on water power, manpower, steam power, and fuels. This was accomplished by the development of the science of thermodynamics which furnished man a common denominator for all forms of energy-conversion devices. The thermodynamics of Carnot, which provided a 
cornerstone for industrial revolution, was a science which treated the physical world in a microscopic sense. It did not look into the inner working of the atom. The essential difference between the Industrial Revolution and the Scientific Revolution lies : in the fact that man is now able to bring to his union of science and craftsmanship a knowledge of the internal mysteries of the atom itself. His engineering can now be applied at the atomic and molecular level.

The state of technology in every age has depended on man's ability to convert and control energy. The opportunities that are now presented for advancement in energy conversion and control are breath-taking in their magnitude. New methods of energy conversion from solar, chemical, and nuclear sources which will be useful to all mankind are being pioneered in the space program. Direct conversion of energy in the sun's rays to electricity by means of the solar cell, the fuel-cell which generates electricity with water as a byproduct, and the light but rugged nuclear-powered space power system are examples. Precise methods of automatic energy control at all levels has become possible through electronics. Although this area of technology was neglected for many years because of man's own superb qualities as a black-box controller, it has advanced in the last two decades through the impetus of military and space programs.

In the earliest days of our Republic human labor furnished a quarter and the labor of animals half of the energy that was required for life. In 1900, each man, woman and child in the United States had two horsepower working for him day and night. At the present time the figure stands at about ten horsepower. With less than ten percent of the world's population, we control almost half of its supply of power, and as a result our standard of living is seven times the average of the rest of the world. To an unprecedented extent, Americans have opportunities for education, recreation and the nobler things of life because of the machine energy that is available to them. Had we lived in the Periclean Age of ancient Greece we should need the exhausting labor of ten billion slaves to provide these same benefits. Such is our debt to modern technology.

I should like to turn now to even more important corollary questions of how this explosion can be absorbed in the fabric of society. The late President Bowman of Johns Hopkins University once said that "every man who puts fire and light into the hands of men puts also beside them a wrath and a violence, a gift and a penalty. "Realization of President Bowman's observation has prompted many to decry the advancements of science as contrary to the good of man. I recall the New Yorker cartoon in which the young boy informed his grandmother that he planned to be a scientist 
when he grew up. His grandmother replied "What a pity, isn't there enough trouble in the world already?"

It seems to me the parable of the ten talents is given its supreme test here. Modern science and technology is like the ten talents. The man afraid of the opportunities made available because of the difficulties presented is like the man in the parable who received from his master one talent, and being afraid of the responsibility, wrapped it in a napkin and buried it. It is patently easy to say that we must bend this colussus to our bidding. But, how shall it be done? We have reached a state in modern technology when science will present many new steps, even giant steps. The emerging questions of importance are those which inquire if it is economically or socially, or even politically, desirable to take a given step. Many options which science permits have profound effects on national security or on our nation's image in the world. Many are clearly beyond individual private enterprise indeed, they are at the level of national efforts.

What then are the instruments available for controlling or regulating science and making critical decisions? There is first the apparatus of the Federal Government. We often observe with dismay the strong coupling between science and the Federal Government. The most visible element of this coupling is funding. More than 60 per cent of all research and development monies are furnished by the Federal Government. Although science is the handmaiden of virtually every agency of government, the largest portion of our $R \& D$ monies are directed toward the technologies of war and its supporting apparatus. Large numbers of today's scientists and engineers are members of a group working to increase military power, who have never worked on anything but weaponry and who are dedicated to the development of a succession of weapons systems.

But when we look at the past, we find that the same pattern always existed. Early government support of science seems to have been based more upon fear of foreign enemies and disease than upon real understanding. The National Academy of Sciences was born on March 3, 1863, the day on which the Conscription Act of the Civil War was signed by President Lincoln. The National Research Council of the National Academy of Science was formed by President Wilson in 1916 under the stimulus of World War I. Under the stimulus of the same war--in 1915--was born the National Advisory Committee for Aeronautics, or NACA, which failed of coming into existence until war shadows loomed. Forty-three years later, NACA had grown into the strong nucleus of research talent upon which the NASA was built. The biggest surge of government involvement of all was caused by the exploitation of the atom in World War II and afterward. 
The legislative and executive apparatus required for handling federal $R \& D$ appropriations and spending must be highly competent. In the first instance, members of Congress are called upon to weigh the merits of thousands of complex projects representing billions of dollars. Committees are assigned in both branches of the Congress to specific areas of the program. This is a monumental task repeated each year by your representatives in Washington. Then there is the executive task of wisely and prudently disbursing the funds to literally thousands of universities, non-profit organizations and industrial firms.

By what means should this increasingly complex management task be accomplished? At least part of the answer is clear. It must continue to be accomplished by scientists and engineers within the Government. It is often argued that since most creative scientists and engineers are outside the Government, science and technology in the public interest should be handled by outside entities. This approach extends back as far as 1820 when the Government gave the Franklin Institute in Philadelphia, a non-profit institution, a contract to study explosions in steam boilers. In the last quarter-century, non-profit organizations serving the Government have been extremely effective in research and in advising. However, during the same period we have learned also that the authority and responsibility to direct science and technology through the disbursement of public funds in the public interest cannot be relinquished. What then must be the nature of government institutions which can protect the public interest, and at the same time realize the full promise of science? By what mechanisms can these institutions make decisions that relate new scientific steps to national policy and public welfare?

The National Aeronautics and Space Administration has evolved a method of scientific management which, we believe, forms a prototype for the future. At the heart of this scheme we find direction, not by professional managers, but by professional scientists and engineers who are themselves engaged in work at the boundaries of their science or technology. Ten field centers consisting of some 30,000 people comprise the instruments by which the space program is managed in behalf of the Government. In this process, some 90 percent of NASA's appropriated funds are spent for R\&D outside the government, and 10 per cent for R\&D within the field center laboratories. The possibilities for creative work within the field centers, provided by the 10 per cent fraction, is the key to maintenance of a highly competent corps of professionals within the Government Service.

We have met tonight to honor a great university and her alumni. I have not yet mentioned the role of the university in the Scientific Revolution. Most of us think of a university as an institution of higher learning 
whose major function is gaining and distributing knowledge. Universities have learned from centuries of experience that the gaining and the distribution of knowledge, or, in other words, research and teaching, are interrelated.

The criterion for a great university has been excellence in both research and classroom teaching. But I wonder if this alone will be enough a decade from now. James E. Webb, Administrator of NASA, has said "How, in an increasing technical age, can the business and industry of the nation remain abreast of the enormous volume of new knowledge which is becoming available in science and technology? How indeed, except by turning to the university and its scholars as a trusted source of information? Such trusted sources are hard to find in our society, but are indispensable to our peculiarly American decision making processes. "

Because of the complexity of the scientific revolution, the university will find itself in a position of leadership in its own community. Broader interpretations of the function of gaining and distributing knowledge will be required. The traditional role of education in the sciences and engineering must be continued and strengthened.

The need here is for high quality and not quantity. There is no shortage of scientists and engineers. There is only a shortage of qualified scientists and engineers. An even greater role must be assured in continuing education. The practicing scientist and engineer may soon need to spend one year out of every ten in refurbishment of his professional knowledge. The university will be called on to increase by orders of magnitude its capacity to store and distribute the expanded body of scientific knowledge. The conventional library, for example, with its storage of information on printed pages will be inadequate for this purpose. The university, acting as a closely coordinated entity, as well as its individual scholars, will be called upon increasingly to aid the Government at all levels in its decision making.

Finally, it will be up to the university to see that modern man is a culturally integrated individual familiar with the sciences as well as the humanities. There cannot be two cultures, simply because the world presents us with only one society in which to live. Dean George Harrison of M. I. T. in his book entitled "What Man May Be" recounts the story of a watch given to Martin Luther. It was the latest 1527 model, larger than a present-day alarm clock. Luther became so excited over his new device that he decided to study mathematics so that he could understand how his watch operated. This showed the fine inquiring spirit of a man whose main 
interest lay in other directions. Luther's modern counterparts in all walks of life, and especially in positions of public and private leadership-and certainly our spiritual leadership -- should understand as well as possible the methods and results of science.

I do not know if you recall the story, in the days of Sputnik I, of the two Latin scholars having lunch at Cambridge. One said, "I say, old chap, what do you think of the Sputnik and all that sort of thing?" The other replied, "A most disturbing state of affairs, old fellow -- just when all this technical thing was dying down."

I should like to conclude my remarks with some observations about that portion of science and technology in transition with which I am most familiar -- the nation's aeronautics and space program.

To look ahead and respond when national needs or objectives require new aeronautical or space systems, goes to the heart of the national interest. We can recall how the United States, despite initial positions of advantage, failed to carry forward advanced work in aeronautics, in jet propulsion, in ballistic missiles, and in rocket vehicle systems necessary for space exploration. The result in each case was that other nations moved ahead, placing the United States in jeopardy and requiring an enormously costly effort to catch up. Dr. Hugh L. Dryden, Deputy Administrator of NASA, has said, "We must not delude ourselves with any thought that leadership in this fast moving age can be maintained with anything less than determined, wholehearted, sustained effort "

NASA, in addition to its space responsibilities, has the duty to advance technology for the design, construction and operation of aircraft. This requires ground-based research facilities including a large array of wind tunnels, structures and materials laboratories, and simulators. Flight research with operational full-scale aircraft as well as with models is conducted. One of the most vital flight research programs has been the hypersonic X-15, which has pioneered lifting flight in the upper atmosphere on the fringes of space to altitudes as high as 354,000 feet and speeds over 4100 miles per hour.

Long-range basic research studies are carried out in those areas which are fundamental to a wide range of applications in aviation. These include vertical and short take-off and landing aircraft, subsonic private and commercial aircraft, the supersonic transport, and hypersonic aircraft.

The supersonic transport has been the subject of considerable public debate in the United States and that debate promises to become 
even more intense. It is proper that such an undertaking be questioned and debated and that its usefulness to, and effects on, society be assessed fully. How can such a machine be made technically feasible? Will it be economically sound? What should its speed be? These and many similar questions have been posed in this public debate. One often gets the impression, however, that the answers are little more than vague opinion. On the contrary, there is a body of technical knowledge upon which many answers may be assessed with confidence.

This fund of knowledge has been built up by the National Aeronautics and Space Administration in a six-year program of research directed specifically toward the supersonic transport. In 1956, after the design of the B-70 had been established, the NASA commenced an organized program of research directed toward supersonic commercial air transportation. By December 1959, sufficient technical information had been generated from research to indicate the technical feasibility of a commercial supersonic transport. On December 11, 1959, NASA brought this information to the attention of the Federal Aviation Agency, and a national program for the development of such a vehicle was proposed.

Although overall technical feasibility was established in a preliminary way, NASA's researches on the most difficult problems continued and they formed an important technical base on which the decision was made by President Kennedy, in June 1963, to undertake the development of a supersonic transport.

A recent move has been instituted at our Lewis Research Center, in Cleveland, to undertake additional studies and investigations in airbreathing propulsion in the range of interest for the supersonic transport, up to Mach 3.0.

Your nation's space program has moved in its nearly six year existence from the capability to put modest satellites weighing a few pounds in near-earth orbit to the Saturn I vehicle which has lifted over ten tons into the same near-earth orbit.

Incidentally, we plan to employ the weight lifting capability of the Saturn I boosters to orbit three giant satellites spanning 96 feet to measure the meteoroid content of space near the earth. These will provide us with vitally needed information on the nature of the meteoroid hazard. Our program is rapidly moving on to the Saturn $V$ space booster and the Apollo three-man spacecraft which will provide our nation, within this decade, the technology to permit man to travel, explore, and use the space around the earth outward to the moon. 
What is this Saturn $V$ space booster and its spacecraft which will give us such powers for space exploration? It is a three-stage device, the first stage of which will lift six million pounds from the earth's surface at Cape Kennedy to a speed of 6,000 miles per hour. Each of the five engines of the first stage has a thrust of 1,500,000 pounds and each engine consumes three tons of fuel and oxygen per second. At 6,000 miles per hour, the five engines of the first stage drop off and fall into the ocean this side of Africa. The second stage takes over and speeds the vehicle to 15,000 miles per hour, at which time the second stage engines drop into the Pacific between Africa and Australia. The third stage injects the remaining part of the Saturn $V$ rocket and the Apollo spacecraft into the earth orbit, and after it has coasted around the earth once, the stage fires again to send off to the moon the 45-ton Apollo spacecraft. After the Apollo spacecraft has achieved an orbit about the moon, two of the astronauts will board a small Lunar Excursion Module and depart for the lunar surface.

They will approach the lunar surface undoubtedly staring intently through their viewing ports. A quick decision will be required whether to land or return to their mother ship and their companion orbiting 90 miles above the lunar surface. On coming to rest on the surface, they will stand in awe of the grandeur of their surroundings. Twice the number of stars seen from earth will be visible overhead. It is the time of the "full earth" and our planet will appear as a huge sphere glowing in bluish-white brilliance. About five hours will be available to make photographs, collect samples and set up instruments to relay information to the earth. Movement will be easy in the low gravitational field.

After ascending to rendezvous with the orbiting Command Module, they begin their 70-hour journey homeward. Their safe return will depend on precise navigational accuracy -- equivalent to shooting the nap off a tennis ball at 100 yards without hitting the ball. If their approach corridor is too shallow they will skip out of the atmosphere and be hurled back into space...... if too steep, abrupt deceleration in the thickening air will crush their fragile shell. Finally, by parachute the Apollo capsule is brought to rest on earth in the Southwest part of the United States.

Preparing for still greater possibilities of the future I can report that only yesterday a suborbital space experiment known as Project Fire, achieved a top velocity over 37, 800 feet per second (about 26, 000 miles per hour) through launch of an Atlas from Cape Kennedy. The experiment, conducted by NASA's Langley Research Center, thus recorded the highest speed ever reached by a man-made object in free flight. The velocity package of instruments burned out in the atmosphere and plunged into the South Atlantic. 
Although it is too early to expect any definitive data from this experiment, we believe we have obtained much useful information for our future programs on the magnitude of heating and structural problems in reentry from flights beyond the moon. Flights returning to earth from a planetary journey may have to enter the earth's atmosphere at speeds as high as 30,000 miles per hour.

If our nation can achieve such strides in space during the first decade or so in its space program, it is logical to ask, what next? As I implied earlier, the scientist and engineer cannot answer what is next. They can only answer by outlining the options which science will permit as the next step. What is in fact done next must be determined by an assessment of the social, economic and political implications of these options.

What then are some of the options? Exploration and extended visits on the lunar surface will be well within our power after Apollo. Large manned space stations weighing many many tons may be placed over fixed points on the surface of the earth. These stations may serve as switchboards in space to route telephone, radio and television from continent to continent and from earth to space vehicles, and to the planets beyond. As our capacity to produce power in space from nuclear energy develops, satellite television will be able to transmit on a world-wide basis directly to the home, without the need of intermediate ground stations. Worldwide weather coverage by satellite is certain to become, eventually, a permanent tool in the art and science of weather prediction. The development of nuclear rockets and nuclear-electric engines will provide man with the capacity of exploring the far reaches of the solar system, with the planets Venus and Mars as the next targets of interest after the moon. A round trip to Venus would require nearly a year, and to Mars eighteen months.

If my standing in the actuarial tables remains fixed, I expect to see man reach Mars and Venus. By the end of the century we should have the capability to dispatch unmanned probes to the outermost fringes of the solar system.

Now, for the first time, man is beginning to grasp the magic key of space technology by which he may unlock the riddles of the origin of the solar system and answer the question of whether life exists on other celestial bodies. Do the seasonal changes in color on the surface of Mars mean that plant life seasonally blooms, withers and dies? Are there living things in the searing winds beneath the covering clouds of Venus? What secrets of the solar system can be wrested from the primordial rocks 
of the lunar surface? Is Jupiter ice encrusted beneath the hydrogen shroud? Reaching into space and finding answers to questions such as these will require resolution and courage. It will test man's mind and heart and sinew as no adventure in history has. No man alive today can forsee the dividends which will follow from the knowledge gained in this great effort

Thank you and good evening. 